\title{
Methods in Pathology
}

\section{Next-generation sequencing-based multi-gene mutation profiling of solid tumors using fine needle aspiration samples: promises and challenges for routine clinical diagnostics}

Rashmi Kanagal-Shamanna, Bryce P Portier, Rajesh R Singh, Mark J Routbort, Kenneth D Aldape, Brian A Handal, Hamed Rahimi, Neelima G Reddy, Bedia A Barkoh, Bal M Mishra, Abhaya V Paladugu, Jawad H Manekia, Neda Kalhor, Sinchita Roy Chowdhuri, Gregg A Staerkel, L Jeffrey Medeiros, Rajyalakshmi Luthra and Keyur P Patel

Department of Hematopathology, The University of Texas M.D. Anderson Cancer Center, Houston, TX, USA

\begin{abstract}
Increasing use of fine needle aspiration for oncological diagnosis, while minimally invasive, poses a challenge for molecular testing by traditional sequencing platforms due to high sample requirements. The advent of affordable benchtop next-generation sequencing platforms such as the semiconductor-based lon Personal Genome Machine (PGM) Sequencer has facilitated multi-gene mutational profiling using only nanograms of DNA. We describe successful next-generation sequencing-based testing of fine needle aspiration cytological specimens in a clinical laboratory setting. We selected 61 tumor specimens, obtained by fine needle aspiration, with known mutational status for clinically relevant genes; of these, 31 specimens yielded sufficient DNA for next-generation sequencing testing. Ten nanograms of DNA from each sample was tested for mutations in the hotspot regions of 46 cancer-related genes using a 318-chip on Ion PGM Sequencer. All tested samples underwent successful targeted sequencing of $\mathbf{4 6}$ genes. We showed $100 \%$ concordance of results between next-generation sequencing and conventional test platforms for all previously known point mutations that included BRAF, EGFR, KRAS, MET, NRAS, PIK3CA, RET and TP53, deletions of EGFR and wild-type calls. Furthermore, next-generation sequencing detected variants in 19 of the $31(61 \%)$ patient samples that were not detected by traditional platforms, thus increasing the utility of mutation analysis; these variants involved the APC, ATM, CDKN2A, CTNNB1, FGFR2, FLT3, KDR, KIT, KRAS, MLH1, NRAS, PIK3CA, SMAD4, STK11 and TP53 genes. The results of this study show that next-generation sequencing-based mutational profiling can be performed on fine needle aspiration cytological smears and cell blocks. Next-generation sequencing can be performed with only nanograms of DNA and has better sensitivity than traditional sequencing platforms. Use of next-generation sequencing also enhances the power of fine needle aspiration by providing gene mutation results that can direct personalized cancer therapy. Modern Pathology (2014) 27, 314-327; doi:10.1038/modpathol.2013.122; published online 2 August 2013
\end{abstract}

Keywords: fine needle aspiration cytology; ion PGM sequencer; next-generation sequencing

Personalized therapy by identification and targeting of tumor-specific molecular abnormalities is rapidly becoming an important component in the management of cancer patients. Consequently, algorithms for tumor diagnosis necessitate not only morphological and immunophenotypic assessment of tumors

Correspondence: Dr KP Patel, MD, PhD, Department of Hematopathology, The University of Texas M.D. Anderson Cancer Center, 8515 Fannin Street, Houston, TX 77054, USA.

E-mail: kppatel@mdanderson.org

Received 2 January 2013; revised 9 May 2013; accepted 11 May 2013; published online 2 August 2013 but also molecular mutational profiling. Among the solid tumors, mutational status is important to the clinical management of patients with thyroid carcinomas, non-small cell carcinomas of the lung, melanomas and colorectal carcinomas. For example, treatment of patients with non-small cell carcinoma of the lung depends on the histological type (adenocarcinoma versus squamous cell carcinoma) and the mutational status of the epidermal growth factor receptor $(E G F R)$ and KRAS genes. ${ }^{1}$ Thus, adequate tissue sampling is essential not only for pathological diagnosis but also for molecular testing that is required to guide therapeutic decisions. ${ }^{1-3}$ 
In clinical practice, minimally invasive fine needle aspiration (FNA) is a helpful and convenient method for establishing the diagnosis of solid tumors. FNA procedures are included in the recommended guidelines for the diagnosis of thyroid carcinomas, ${ }^{4,5}$ lung carcinomas ${ }^{6,7}$ and sarcomas, such as Ewing Sarcoma/primitive neuroectodermal tumor. $^{8}$ Although the DNA yield obtained by FNA is adequate for morphological diagnosis, FNA material is not routinely processed for molecular analysis. ${ }^{9}$ This is because mutational assessment of multiple genes by traditional sequencing platforms require a large quantity of DNA, which is often difficult to obtain by FNA. Fortunately, most FNA procedures routinely have either a concurrent biopsy or a follow-up surgical excision, which provide adequate tissue for molecular assessment. ${ }^{10,11}$

In some instances, however, cytological specimens may be the only material available for molecular testing. If the tumor is locally advanced or metastatic, surgical resection is not performed., ${ }^{1,6}$ In some patients, tumor size, location or co-morbid conditions may preclude concurrent core needle or excisional biopsy. ${ }^{1}$ Therefore, efficient strategies and novel technologies are needed to apply molecular testing to FNA samples. Studies have attempted to improve the yield of DNA from cytological samples by using Fast Technology for Analysis cards for high-quality DNA preservation. ${ }^{9}$ Preparation of cell blocks using the tissue coagulum clot method has also increased the efficacy of tissue extraction from endobronchial and transbronchial FNA samples. ${ }^{1}$ Additionally, use of COLD-PCR/direct sequencing for EGFR and KRAS detection in lung aspirates and locked nucleic acid-based PCR/sequencing assay in thyroid aspirates has improved the sensitivity of mutation detection. ${ }^{10,12}$

Massively parallel or next-generation sequencing (NGS) technology is increasingly being used for mutational analysis of tumors for both clinical and research applications. The advent of affordable bench top NGS platforms such as Ion Personal Genome Machine (PGM) has facilitated multi-gene mutational profiling using only nanograms (ng) of DNA. ${ }^{13}$ PGM uses the semiconductor-based sequencing technology, which monitors the release of hydrogen ions during the incorporation of nucleotide. The resulting $\mathrm{pH}$ change detected by the ionsensitive field-effect transistor is converted into sequence information by signal-processing software. ${ }^{14}$ The need for extremely small amount of DNA makes this technology potentially applicable to FNA cytological specimens in a clinical laboratory. To our knowledge, no studies using NGS on cytology specimens have been reported to date.

The objective of this study was to evaluate the feasibility of applying NGS technology to the mutational analysis of routinely obtained FNA cytological specimens in a clinical molecular diagnostic laboratory.

\section{Materials and methods}

\section{Case Selection/Patient Specimens}

For this study, we selected FNA-obtained samples from 61 consecutive tumor specimens with known mutational status for clinically relevant genes between January 2010 and August 2012. The diagnoses of these samples were established using universally accepted criteria. Specimens included 33 smears and 28 formalin-fixed, paraffin-embedded cell blocks. Smears were stained with either DiffQuik (methanol-fixed) or Papanicolaou (ethanolfixed). The cell block sections were stained with hematoxylin and eosin. All slides were reviewed by pathologists to circle the tumor-rich areas and estimate the tumor percentage. Only cases in which tumor involvement was estimated to be $>20 \%$ were included in this study.

\section{DNA Extraction from FNA Smears and Cell Blocks}

DNA was extracted directly from stained FNA smear(s). Coverslips were removed using xylene followed by hydration and air drying. Circled tumorrich areas were scraped off the slides using a razor blade by manual microdissection. For cell blocks, DNA was extracted from a variable number of unstained sections, each $0.4 \mu \mathrm{m}$ thick. Manual microdissection of tumor-rich areas was followed by deparaffinization. DNA was extracted using the Pico Pure DNA Extraction Kit (Arcturus, Mountain View, CA) followed by purification using the Agentcourt AMPureXP kit (Agentcourt Biosciences, Beverly, MA). DNA quantification was performed using Qubit DNA HS assay kit (Life Technologies, Carlsbad, CA). Only samples with a minimum DNA concentration of $0.8 \mathrm{ng} / \mu \mathrm{l}$ were selected for NGS.

\section{Next-Generation Sequencing}

Library preparation and emulsion PCR. An amplicon library was generated from $10 \mathrm{ng}$ of DNA from each sample using the Ion Ampliseq Cancer Panel (Life Technologies). Formalin-fixed, paraffin-embedded cell pellets of the H2122 cell line diluted in the HL60 cell line were used as control. The 46 genes in the panel for detection of 'hotspot' mutations included: AKT1, BRAF, FGFR1, GNAS, IDH1, FGFR2, KRAS, NRAS, PIK3CA, MET, RET, EGFR, JAK2, MPL, PDGFRA, PTEN, TP53, FGFR3, FLT3, KIT, ERBB2, ABL1, HNF1A, HRAS, ATM, RB1, CDH1, SMAD4, STK11, ALK, SRC, SMARCB1, VHL, MLH1, CTNNB1, KDR, FBXW7, APC, CSF1R, NPM1, SMO, ERBB4, CDKN2A, NOTCH1, JAK3, and PTPN11. Primers for PCR amplification included the 190-primer pair pool (provided by the vendor) with an additional primer pair that was custom added to cover the 'hotspot' location on codon 17 of AKT1. Following PCR amplification of target sequences, barcodes were ligated to the amplicons 
using the Ion Xpress Barcode Adaptors Kit (Life Technologies). Library quantification was then performed using the Bioanalyzer High Sensitivity DNA Chip (Agilent Technologies, Santa Clara, CA). The library was diluted in nuclease-free water to obtain a final concentration of $16 \mathrm{pM}$. Emulsion PCR was performed manually using the Ion Xpress Template Kit (Life Technologies) followed by manual breaking of the emulsion to isolate the ion spheres (ISPs). The quality of the DNA following PCR was measured using the Qubit IonSphere Quality control kit (Life Technologies). Selective ISPs with DNA were isolated and sequenced on a Ion 316 Chip (4 samples/ chip) or a Ion 318 Chip (8 samples/chip) using the vendor-provided sequencing kit (Life Technologies).

Successful sequencing of a sample required at least 300000 reads with a quality score of AQ20 (1 misaligned base per 100 bases). For a wild-type call, a minimum coverage of $250 \times$ was required. As tumor specimens were admixed with normal tissue, a minimum coverage of $500 \times$ with at least $10 \%$ frequency was used as cutoff for a variant to be considered true. All variants detected by Ion PGM with at least $10 \%$ frequency were selected for confirmation by alternate platforms.

\section{Data Analysis}

Sequence alignment and base calling was performed by Torrent Suite software V2.0.1 (Life Technologies) using Human Genome Build 19 (Hg19) as the reference. Torrent Variant Caller software V1.0 (Life Technologies) was used for the detection of variants whereas the Integrative Genomics Viewer (IGV) was used to visualize variants. ${ }^{15}$ The IGV provides a visual picture of the sequence alignment with the reference, thus facilitating detection of false variants as a result of possible sequencing errors or strand bias. Oncoseek software, developed by one of us (MJR), was used to integrate the data generated by Torrent variant caller for annotation and visualization in IGV. ${ }^{16}$ Further, it was used to generate refined data by filtering errors generated due to the presence of homopolymers. Other custom-designed tools in Oncoseek include ready annotation of the results using standard nomenclature and side-by-side comparison between specimens. During interpretation of NGS data, the results of the traditional mutation analysis were completely blinded.

\section{Confirmation of Mutations by Traditional Sequencing Platforms: Sanger Sequencing, Pyrosequencing and Sequenom Massarray System}

At least one of the three conventional platforms was used to confirm the results obtained by the Ion Ampliseq Cancer Panel in our clinical laboratory. The results derived by using the Ion Ampliseq Cancer Panel were confirmed by at least one of the three conventional platforms used in our clinical laboratory. For Sanger sequencing, PCR amplification of genomic regions of interest was performed using $10 \mathrm{ng}$ of DNA template and M13-tagged primers; M13 forward, 5'-TGTAAAACGACGGCCAGT-3'; or M13 reverse, 5'-CAGGAAACAGCTATGACC- $3^{\prime}$. Primers were designed and optimized to ensure similar PCR conditions for all the genes. PCR amplification was followed by purification using AMPure magnetic beads (Agentcourt). Sanger sequencing was performed on a 3730 DNA Analyzer (Applied Biosystems, Carlsbad, CA) using $5 \mu \mathrm{l}$ of PCR product (1:5 dilution in water) and analyzed using SeqScape v2.5 and/or v2.7 software (Applied Biosystems). For pyrosequencing, PCR amplification was confirmed by electrophoresis on an agarose gel. In all, $15 \mu$ l of the PCR product along with the appropriate sequencing primer underwent pyrosequencing in PSQ96 HS System (Biotage AB, Uppsala, Sweden). The program of nucleotide dispensation order was customized to each of the genes to detect all possible mutations. The Sequenom multiplex assay was used to assess the mutational status of hotspot regions in 11 genes: $A K T 1, B R A F$, GNAS, GNAQ, IDH1, IDH2, KRAS, MET, NRAS, PIK3CA, and RET. PCR amplification was performed using $10 \mathrm{ng}$ of DNA in each of the nine wells and designed primers from Integrated DNA Technologies (Coralville, IA), designed by using Sequenom's MassARRAY Designer software. Dephosphorylation of unincorporated nucleotides was performed using shrimp alkaline phosphatase. Single base primer extension using mass modified di-deoxy nucleotides (iPLEX Gold kit) was followed by product analysis using MALDI-TOF mass spectrometry (Sequenom).

\section{Results}

\section{Case Selection}

Sixty-one consecutive cytological tumor specimens obtained by FNA and in which mutation analysis of selected genes had been requested as a part of clinical care were selected for the study group. Fiftyfive cases $(n=55)$ had been tested by one of the conventional testing platforms and six cases were primarily received for NGS testing. The minimum DNA concentration required for successful NGS analysis using the Ion PGM platform is $10 \mathrm{ng}$. The minimum amount was based purely on validation studies performed on surgical biopsy specimens (data not shown). The above required DNA concentration was obtained in 31 of the $61(51 \%)$ samples derived from 15 cell blocks and 16 aspirate smears. These samples were selected for NGS-based testing. In the remaining cases, 17 of the $33(52 \%)$ FNA smears and 13 of the 28 (46\%) cell blocks yielded suboptimal DNA and were not tested by NGS. However, all of these 'failed' cases were successfully analyzed by one of the conventional testing platforms for mutations in $\geq 1$ genes. 
Table 1 Clinico-pathological data and specimen characteristics of the cytological cases that qualified for testing by Ion Torrent's nextgeneration sequencing

\begin{tabular}{|c|c|c|c|c|c|c|}
\hline Case no. & Site & Diagnosis & Tumor \% & Stain type & Slides used & $\begin{array}{c}\text { DNA yield } \\
\text { (ng/ul) }\end{array}$ \\
\hline \multicolumn{7}{|l|}{ Smears } \\
\hline 1 & Thyroid & Papillary thyroid carcinoma & 70 & Рар & 2 & 2.00 \\
\hline 2 & LN & Papillary thyroid carcinoma ${ }^{a}$ & 90 & Pap & 1 & 3.14 \\
\hline 3 & Thyroid & High grade carcinoma & 95 & Pap & 1 & 2.07 \\
\hline 4 & LN & Adenocarcinoma, lung ${ }^{\mathrm{a}}$ & 70 & Рар & 1 & 21.00 \\
\hline 5 & $\mathrm{LN}$ & Adenocarcinoma, lung ${ }^{\mathrm{a}}$ & 60 & DQ & 1 & 12.70 \\
\hline 6 & LN & Adenocarcinoma, lung ${ }^{\mathrm{a}}$ & 60 & DQ & 1 & 3.83 \\
\hline 7 & Lung & Adenocarcinoma, lung & 80 & Рар & 1 & 4.78 \\
\hline 8 & LN & Adenocarcinoma, lunga & 60 & Pap & 2 & 1.32 \\
\hline 9 & Pleural fluid & Adenocarcinoma, lung ${ }^{\mathrm{a}}$ & 25 & Pap & 1 & 2.70 \\
\hline 10 & LN & Adenocarcinoma, lung ${ }^{\mathrm{a}}$ & 80 & Pap & 1 & 0.30 \\
\hline 11 & LN & Non-small cell carcinoma, lunga & $>20$ & Pap & 2 & 7.71 \\
\hline 12 & LN & Adenosquamous carcinoma, lunga & 50 & Pap & 1 & 7.63 \\
\hline 13 & Liver & Adenocarcinoma, colorectal ${ }^{\mathrm{a}}$ & 90 & Рар & 1 & 1.17 \\
\hline 14 & LN & Melanoma $^{\mathrm{a}}$ & $>20$ & Pap & 2 & 0.91 \\
\hline 15 & LN & Melanoma $^{\mathrm{a}}$ & 100 & DQ & 1 & 8.64 \\
\hline 16 & LN & Pheochromocytoma $^{a}$ & 70 & Pap & 1 & 2.90 \\
\hline \multicolumn{7}{|l|}{ Blocks } \\
\hline 17 & LN & Medullary thyroid carcinoma ${ }^{a}$ & 50 & NA & 4 & 1.71 \\
\hline 18 & LN & Adenocarcinoma, lung ${ }^{\mathrm{a}}$ & 35 & NA & 4 & 1.93 \\
\hline 19 & Lung & Adenocarcinoma, lung & 60 & NA & 6 & 1.28 \\
\hline 20 & Lung & Adenocarcinoma, lung & 50 & NA & 1 & 13.80 \\
\hline 21 & Lung & Adenocarcinoma, lung & 75 & NA & 5 & 4.85 \\
\hline 22 & Pleural fluid & Adenocarcinoma, lung ${ }^{\mathrm{a}}$ & 70 & NA & 2 & 0.28 \\
\hline 23 & Lung & Adenocarcinoma, lung & 30 & NA & 7 & 1.40 \\
\hline 24 & Pleural fluid & Adenocarcinoma, lung ${ }^{\mathrm{a}}$ & 80 & NA & 4 & 3.03 \\
\hline 25 & Pleural fluid & Adenocarcinoma, lung ${ }^{\mathrm{a}}$ & 80 & NA & 3 & 1.48 \\
\hline 26 & Lung & Adenocarcinoma, lung & 60 & NA & 7 & 14.50 \\
\hline 27 & LN & Squamous cell carcinoma, lunga & 85 & NA & 3 & 1.43 \\
\hline 28 & Bone & Adenocarcinoma, prostate $^{\mathrm{a}}$ & 50 & NA & 4 & 1.32 \\
\hline 29 & LN & Melanoma $^{\mathrm{a}}$ & 95 & NA & 10 & 1.79 \\
\hline 30 & $\mathrm{LN}$ & Melanoma $^{\mathrm{a}}$ & 25 & NA & 4 & 2.94 \\
\hline 31 & Soft tissue ${ }^{b}$ & Alveolar soft part sarcoma & 80 & NA & 4 & 0.85 \\
\hline
\end{tabular}

Abbreviations: LN, lymph node; NA, not applicable.

DNA extracted from these cases met the minimum required concentration as measured by Qubit.

${ }^{\mathrm{a}}$ Metastatic from a primary tumor.

belvic site.

\section{Specimen Characteristics}

The clinical and pathological information of the 31 patient specimens assessed by NGS in this study are described in Table 1. The tumors included 16 cases of primary or metastatic adenocarcinomas of the lung, 4 cases of metastatic melanomas, 4 cases of thyroid carcinomas ( 2 papillary, 1 medullary and 1 high-grade) 2 colonic adenocarcinomas and 1 case each of squamous cell carcinoma of the lung, nonsmall cell carcinoma of the lung, adenosquamous carcinoma of the lung, alveolar soft part sarcoma and pheochromocytoma.

Estimation of tumor burden based on tumor percentage and the number of slides used for DNA extraction of the 31 cases with adequate DNA are shown in Table 1. As a prerequisite, only cases with a tumor percentage $>20 \%$ were selected for performing NGS. The median tumor percentages in the smears and cell blocks were 70\% (range, 25-100, $n=14$ ) and $60 \%$ (range, 25-95, $n=15$ ), respectively. The median number of slides used to extract DNA was 1 for smears (range, 1-2) and 4 for cell blocks (range, 1-10). The median DNA concentration for smears and cell blocks were $3.02 \mathrm{ng} / \mu \mathrm{l}$ (range, 0.295-21) and $1.71 \mathrm{ng} / \mu \mathrm{l}$ (range, 0.276-14.5), respectively. The selected smear samples included both Papanicolaou (ethanol-fixed) and Diff-Quik (methanol-fixed)-stained FNA smears. The process of extraction and yield of DNA was not affected by the type of fixation or staining. Images of the slides used for DNA extraction from these 31 cases are shown in Figure 1.

In comparison, we analyzed the specimen characteristics of 30 cases with suboptimal DNA for NGS testing. The median tumor percentages in the smears and cell blocks were 80\% (range, 30-100) and 65\% (range, 40-90), respectively. The median number of slides used to extract DNA was 1 for smears (range, 1-4) and 3.5 for cell blocks (range, 1-8). The median DNA concentration for the smear and cell block samples were $0.276 \mathrm{ng} / \mu \mathrm{l}$ (range, 0.001-0.673) and $0.001 \mathrm{ng} / \mu \mathrm{l}$ (range, 0.00-0.613), respectively. Based on this, there were no significant differences between the samples that yielded DNA adequate for NGS testing versus the samples that did not yield 

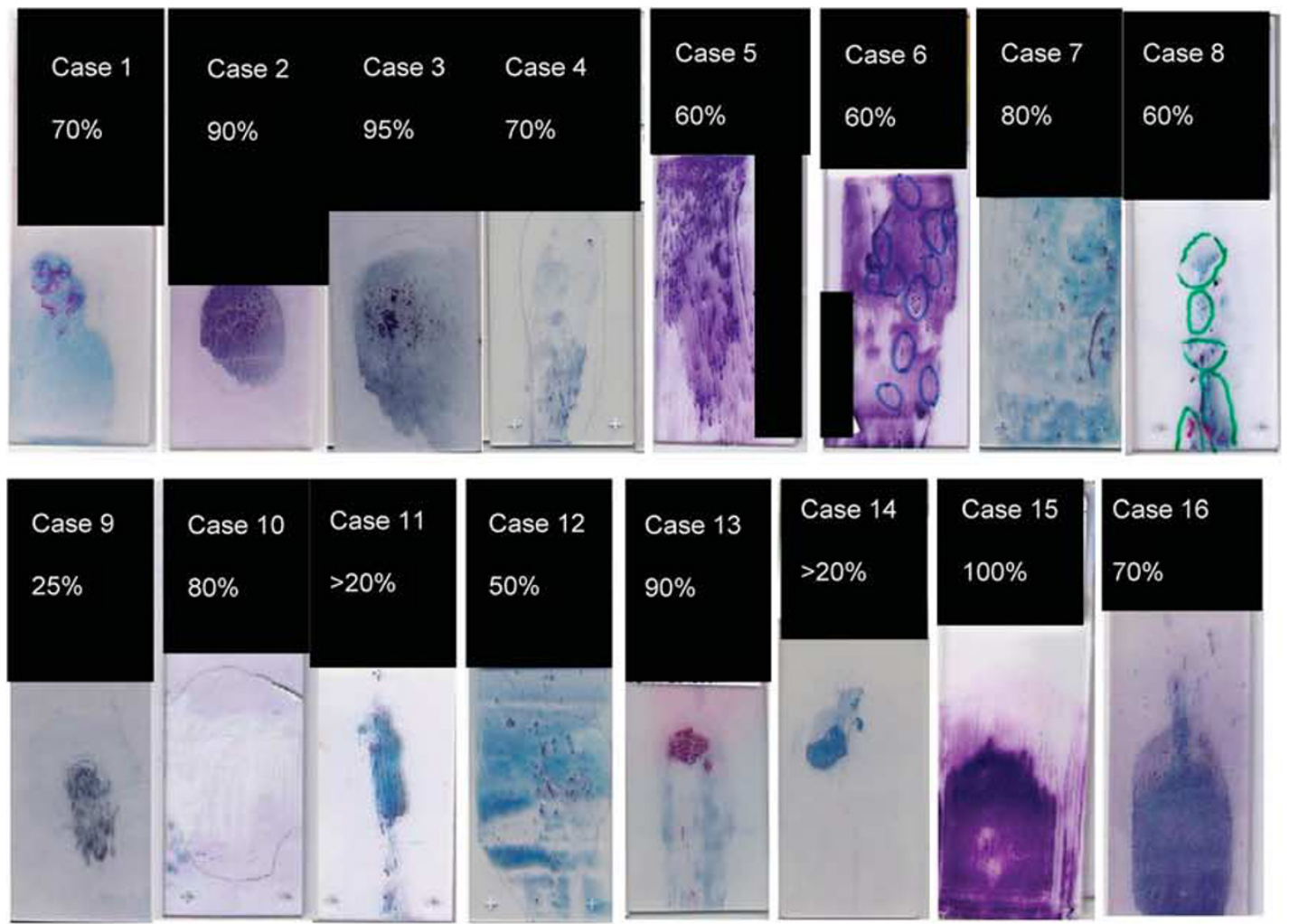

Representative slide images of the FNA smears
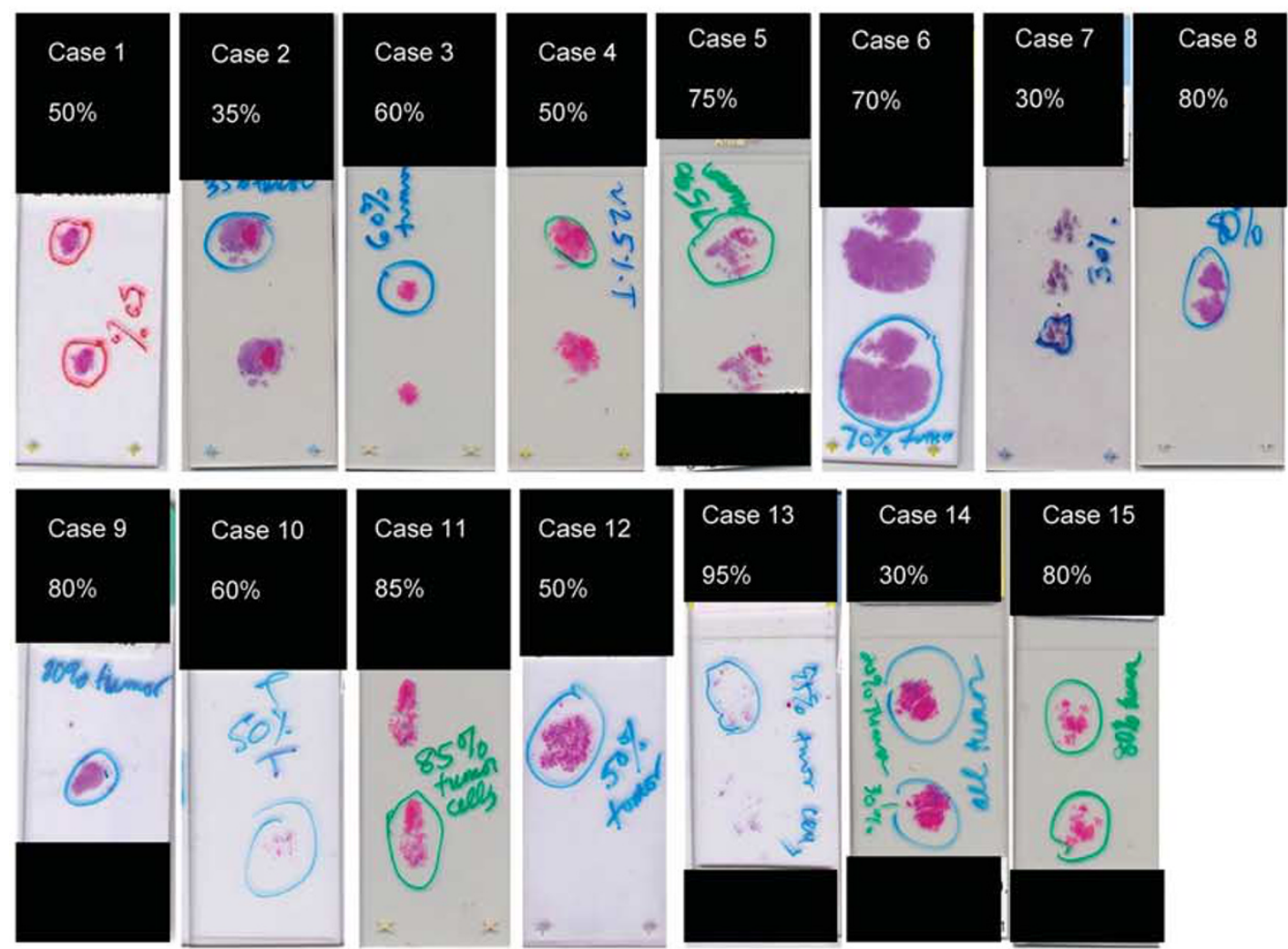

Representative slide images of the cell blocks

Figure 1 Representative image of the FNA smears and cell blocks used for the study. The amount of available material was variable, but these cases had sufficient DNA for analysis. 
Table 2 Performance metrics and detected variants of selected fine needle aspirate smear samples in our study

\begin{tabular}{|c|c|c|c|c|}
\hline $\begin{array}{l}\text { Case } \\
\text { no. }\end{array}$ & Total reads & $\begin{array}{l}\text { Filtered Q20 } \\
\text { reads (\% total) }\end{array}$ & Variants & $\begin{array}{l}\text { Failed amplicons } / \\
\text { genes }(<250 \times \\
\text { coverage })\end{array}$ \\
\hline 1 & 523092 & $429525(82)$ & $\begin{array}{l}\text { NM_004333.4(BRAF):c.1799T >A p.V600E NM_004119.2(FLT3):c.2039C > T } \\
\text { p.A680V }\end{array}$ & TP53 \\
\hline 2 & 744563 & $610704(82)$ & $\begin{array}{l}\text { NM_004333.4(BRAF):c.1799 T > A p.V600E } \\
\text { NM_002253.2(KDR):c.1444 T >C p.C482R }\end{array}$ & CDKN2A \\
\hline 3 & 680436 & $559115(82)$ & NM_000546.5(TP53):c.638G > T p.R213L & KIT \\
\hline 4 & 563731 & $460325(82)$ & $\begin{array}{l}\text { NM_033360.2(KRAS):c.34G > T p.G12C NM_000546.5(TP53):c.475G >C } \\
\text { p.A159Pa }\end{array}$ & \\
\hline 5 & 622091 & $418175(67)$ & NM_033360.2(KRAS):c.37G > T p.G13C & \\
\hline 6 & 711955 & $549189(77)$ & $\begin{array}{l}\text { NM_000141.4(FGFR2):c.1647T >A p.N549K }{ }^{\mathrm{a}} \text { NM_002253.2(KDR):c.1444T >C } \\
\text { p.C482R }{ }^{\mathrm{a}} \text { NM_000222.2(KIT):c.1621A >C p.M541L } \\
\text { NM_000546.5(TP53):c.273G > A p.W91*a }\end{array}$ & None \\
\hline 7 & 810521 & $658770(81)$ & NM_002253.2(KDR):c.3433G >C p.G1145R $\mathrm{R}^{\mathrm{a}}$ & \\
\hline 8 & 555218 & $451324(81)$ & $\begin{array}{l}\text { EGFR exon } 19 \text { 15bp deletion NM_002253.2(KDR):c.1444T }>\text { C p.C482R } \\
\text { NM_006218.2(PIK3CA):c.1030G >A p.V344M }\end{array}$ & FLT3; NOTCH1 \\
\hline 9 & 580104 & $495402(85)$ & NM_000455.4(STK11):c.1062C >G p.F354L ${ }^{\mathrm{a}}$ & \\
\hline 10 & 976974 & $749289(77)$ & $\begin{array}{l}\text { NM_033360.2(KRAS):c.183A > T p.Q61Hª NM_000546.5(TP53):c.892G > T } \\
\text { p.E298*a }\end{array}$ & FLT3 \\
\hline 11 & 553205 & $456865(83)$ & EGFR: p.E745_A750Del15bp exon 19 & $C D K N 2 A, R E T$ \\
\hline 12 & 1154270 & $908330(79)$ & No variants detected & None \\
\hline 13 & 588443 & $480470(82)$ & $\begin{array}{l}\text { APC p.E1306_E1309Del8bp Exon } 16^{\mathrm{a}} \text { NM_000222.2(KIT):c.1621A > C } \\
\text { p.M541L } \\
\text { NM_033360.2(KRAS):c.35G > T p.G12V } \\
\text { NM_006218.2(PIK3CA):c.3062A > Gp.Y1021C NM_000546.5(TP53):c.817C > T } \\
\text { p.R273C }\end{array}$ & TP53 \\
\hline 14 & 1484662 & $1167524(79)$ & $\begin{array}{l}\text { NM_002524.4(NRAS): c.182A > G p.Q61R NM_000546.5(TP53): c.637C > T } \\
\text { p.R213*a }\end{array}$ & \\
\hline 15 & 830528 & 649191 (78) & $\begin{array}{l}\text { NM_000077.4(CDKN2A):c.181G > T p.E61*a NM_002524.4(NRAS):c.181C > A } \\
\text { p.Q61K }{ }^{\mathrm{a}} \text { NM_000546.5(TP53):c.833C }>\text { T p.P278L } \mathrm{L}^{\mathrm{a}}\end{array}$ & \\
\hline 16 & 863550 & $658317(76)$ & No variants detected & $C D K N 2 A$ \\
\hline
\end{tabular}

Variants detected by both conventional and next-generation sequencing (NGS) methods are in bold.

${ }^{a}$ Additional variants detected by NGS method for which conventional testing was not performed.

adequate DNA. We are unable to draw any conclusions about the minimum amount of FNA sample required.

\section{Performance of NGS Testing Using Cytology Specimens}

All 31 samples with adequate DNA underwent successful targeted sequencing of the 46 genes. The median number of filtered Q20 alignment reads for smears was 554152 (range, 167 391-1019698) and for cell blocks was 475299 (range, 418175$1167524)$. All but one smear had an AQ20 read well over the minimum level of $\mathbf{3 0 0} 000$ for analysis. The median filtered AQ20 alignment read for formalinfixed, paraffin-embedded biopsy or resection specimens that were tested on the same runs was 451324 . Thus, both cytological and surgical specimens showed comparable performance metrics. Importantly, neither the fixatives (methanol, ethanol or formalin) nor the stains (Diff-Quik, Papanicolaou stains) seemed to interfere with NGS-based analysis. No significant differences were noted in the depth of coverage achieved between the cytology specimens and biopsy/resection specimens from different patients analyzed on the same NGS run (data not shown). The summary of performance metrics of the specimens including failed amplicons are listed in Tables 2 and 3 and illustrated in Figure 2.

\section{Mutation Results}

The 740 hotspot mutations in 46 genes included multiple targets of oncogenesis, prognosis or therapy. All mutations detected by conventional sequencing platform were also detected by NGS. There was a $100 \%$ concordance between the results of conventional sequencing platforms and NGS. These results are summarized in Tables 2 and 3.

Mutational analysis of genes relevant to the tumor type was performed on every case by one of the conventional platforms. Among the 16 FNA smears, conventional sequencing platforms detected seven single-nucleotide variants (SNVs), including $B R A F$ V600E; KRAS G12C, G12V and G13C; PIK3CA Y 1021C; and NRAS Q61R as well as two indels in the EGFR gene (15 bp deletions in exon 19). Among the cell blocks, conventional sequencing platforms detected seven SNVs, including RET M918T; EGFR L858Rand A750P; MET N375S; TP53 R248W; and $B R A F$ V600E as well as four indels in the EGFR gene (15 bp deletions in exon 19, 9 bp deletions in exon 
Table 3 Performance metrics and detected variants of selected cell blocks prepared from fine needle aspirate samples in our study

\begin{tabular}{|c|c|c|c|c|}
\hline $\begin{array}{l}\text { Case } \\
\text { no. }\end{array}$ & Total reads & $\begin{array}{l}\text { Filtered } Q 20 \\
\text { reads }(\% \text { total) }\end{array}$ & Variants & $\begin{array}{l}\text { Failed amplicons } / \\
\text { genes }(<250 \times \\
\text { coverage })\end{array}$ \\
\hline 17 & 611521 & $456261(75)$ & NM_020975.4(RET):c.2753 T >C p.M918T & \\
\hline 18 & 552230 & $424284(77)$ & $\begin{array}{l}\text { NM_005228.3(EGFR):c.2573 T > G p.L858R NM_000249.3(MLH1):c.1151 T >A } \\
\text { p.V384D }\end{array}$ & \\
\hline 19 & 681281 & $475299(70)$ & EGFR p.K745_A750Del15bp Exon 19 & $C D K N 2 A$ \\
\hline 20 & 615842 & $167391(27)$ & $\begin{array}{l}\text { NM_005228.3(EGFR):c.2573T > G p.L858R NM_000222.2(KIT):c.1621A >C } \\
\text { p.M541L }{ }^{\mathrm{a}} \text { NM_005359.5(SMAD4):c.1414C >A p.P472T }\end{array}$ & $\begin{array}{l}\text { SMO, KIT, RET, } \\
R B 1, A P C, M P L \\
\text { TP53, CDKN2A }\end{array}$ \\
\hline 21 & 444366 & $355738(80)$ & $\begin{array}{l}\text { NM_000051.3(ATM):c.9007A >C p.N3003H } \mathrm{H}^{\mathrm{a}} \text { NM_000051.3(ATM):c.2572T }>\mathrm{C} \\
\text { p.F858L }\end{array}$ & $\begin{array}{l}A P C ; K I T ; R B 1 ; \\
\quad \text { TP53 }\end{array}$ \\
\hline 22 & 592282 & $473115(80)$ & $\begin{array}{l}\text { NM_005228.3(EGFR):c.2239_2248delinsC p.L747fs }{ }^{*} \mathbf{1} \\
\text { NM_005228.3(EGFR):c.2248G }>\text { C p.A750P } \\
\text { NM_002834.3(PTPN11):c.205_211delinsAGAA p.E69fs* } 2^{\mathrm{a}}\end{array}$ & FLT3; RET; KIT \\
\hline 23 & 581392 & $469639(81)$ & No variants detected & NOTCH1; STK11 \\
\hline 24 & 732506 & $599459(82)$ & $\begin{array}{l}\text { EGFR } 9 \text { bp deletion } \\
\text { NM_005228.3(EGFR):c.2248G >C p.A750P } \\
\text { NM_002834.3(PTPN11):c.205_211delinsAGAAp.E69fs* } 2^{\text {a }}\end{array}$ & FLT3 \\
\hline 25 & 1281471 & $1019698(80)$ & $\begin{array}{l}\text { EGFR } 9 \text { bp deletion } \\
\text { NM_000546.5(TP53):c. } 711 \mathrm{G}>\mathrm{A} \text { p.M237 } \mathrm{I}^{\mathrm{a}}\end{array}$ & FLT3 \\
\hline 26 & 724982 & $562360(78)$ & NM_033360.2(KRAS):c.35G > T p.G12V ${ }^{\mathrm{a}}$ & FLT3 \\
\hline 27 & 612845 & $487329(80)$ & No variants detected & $A P C$ \\
\hline 28 & 681281 & $525820(77)$ & $\begin{array}{l}\text { NM_001904.3(CTNNB1):c.98C > A p.S33Y } \mathrm{Y}^{\mathrm{a}} \\
\text { NM_001127500.1(MET):c.1124A }>\text { G p.N375S NM_000546.5(TP53):c.742C > T } \\
\text { p.R248W }\end{array}$ & PTEN, RET \\
\hline 29 & 457378 & $373344(82)$ & NM_002524.4 NRAS: c.182A > T p.Q61L $\mathrm{L}^{\mathrm{a}}$ & \\
\hline 30 & 765725 & $606727(79)$ & $\begin{array}{l}\text { NM_004333.4(BRAF):c.1799 T >A p.V600E NM_000222.2(KIT):c.1621A >C } \\
\text { p.M541L } \mathrm{L}^{\mathrm{a}}\end{array}$ & \\
\hline 31 & 677538 & $546910(81)$ & $\begin{array}{l}\text { NM_000455.4(STK11):c.149T > G p.L50R }{ }^{\mathrm{a}} \text { NM_000546.5(TP53):c.742C > G } \\
\text { p.R248G }\end{array}$ & None \\
\hline
\end{tabular}

Variants detected by both conventional and next-generation sequencing (NGS) methods are in bold.

${ }^{a}$ Additional variants detected by NGS method for which conventional testing was not performed.

19 and exon 20). All of these alterations were accurately detected by NGS platform. An example, each of SNV and indel, is shown in Figure 3 and Figure 4 respectively.

In 12 of the 16 (75\%) FNA smears studied by NGS, in addition to the alterations detected by conventional sequencing platforms, an additional 19 SNVs and 1 indel were identified. The additional variants included FLT3 A680V, KDR C482R, TP53 R213L, TP53 A159P, TP53 W91*, TP53 E298*, TP53 Arg213*, TP53 P278L, FGFR2 N549K, KDR G1145R, PIK3CA V344M, STK11 F354L, KRAS Q61H, KRAS G12V, KIT M541L, CDKN2A E61* and NRAS Q61K. In a single case, an 8-bp deletion in exon 16 of the APC gene (p.E1306_E1309Del8bp) was also detected. Similarly, in 11 of the 15 (73\%) cell blocks studied by NGS, in addition to the alterations detected by conventional sequencing platforms, an additional 16 SNVs and 2 indels were detected. These additional variants included $M L H 1$ V384D, SMAD4 P472T, KIT M541L, CTNNB1 S37F, $A T M$ N3003H, ATM F858L, EGFR A750P, TP53 M237I, KRAS G12V, CTNNB1 S33Y, NRAS G61L and STK11 L50R. An indel in PTPN11 was detected in two cases (NM_002834.3(PTPN11):c.205_211delinsAGAA p.E69fs*2).

We tested six lung adenocarcinoma specimens for indels in EGFR gene. All six cases showed deletion (variable from $9 \mathrm{bp}$ to $15 \mathrm{bp}$ ) of EGFR in exons 19 and 20. Following NGS testing, all cases showed the presence of deletion accurately. In 2 of the 6 cases, deletions were not called by the variant caller. However, deletions were visualized on $\operatorname{IgV}$ viewer.

\section{Discussion}

We have presented data demonstrating that NGSbased testing for gene mutational profiling can be performed reliably using nanogram amounts of DNA obtained from FNA cytology smears and cell blocks. The results of this study thereby enhance the utility of FNA that can be used for routine diagnosis as well as mutation profiling to guide personalized cancer therapy.

Minimally invasive FNA is a commonly used procedure in the workup and diagnosis of solid tumors. FNA is a standard pre-operative diagnostic screening technique, for example, for the workup of patients with thyroid nodules. ${ }^{4,5}$ In fact, the Bethesda standardized system of reporting thyroid lesions is specifically designed for FNA samples. ${ }^{17-19}$ Cytological diagnostic procedures have been included in lung cancer staging guidelines based on the similar diagnostic efficacy compared with surgical excisional biopsies. ${ }^{6,7}$ 

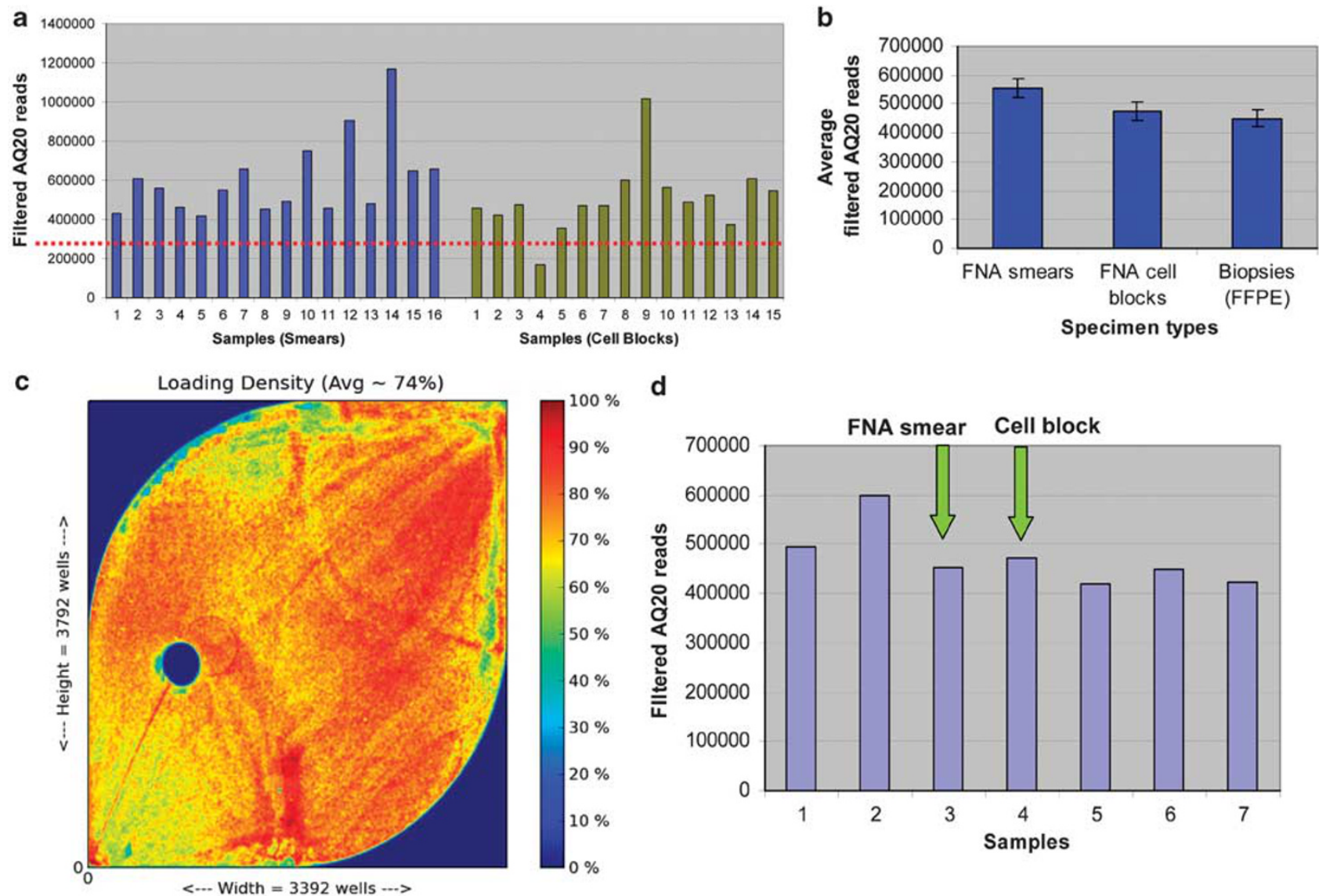

Figure 2 (a) Filtered AQ20 reads of the fine needle aspirate smears (blue, left) and cell blocks (green, right) used in our study. All samples (except case 20, cell block) demonstrated an AQ20 read of over the minimum set at 300000 . (b) Comparable average filtered AQ20 reads from fine needle aspirate (FNA) smears, cell blocks and FFPE material retrieved from excisional biopsies. (c) Representative heat map of wells, ISP, of a representative sample run that included five excisional biopsies (FFPE material), one FNA smear and one cell block; (d) Filtered AQ20 reads from the same run that included five excisional biopsies (FFPE material), one FNA smear (sample 3) and one cell block (sample 4).

Performing mutation analysis on FNA specimens is advantageous for several reasons. First, in situations where the diagnosis is not obvious, mutation data can be used to improve diagnostic accuracy, thus averting unnecessary surgery and associated complications. ${ }^{20-22}$ For example, in thyroid lesions, the indeterminate categories under Bethesda standardized reporting, constitutes almost $30 \%$ of the cases. ${ }^{17-20,23}$ Detection of BRAF mutation in such cases strongly favors a diagnosis of papillary thyroid carcinoma. ${ }^{12,24-27}$ Second, the presence of mutation can help stratify patients into less aggressive or more aggressive groups. ${ }^{12,25,28,29}$ Third, a cytological specimen may be the sole diagnostic material available for a patient's tumor. For example, only a third of the lung carcinomas are resectable at the time of initial presentation. ${ }^{12}$ If the lung mass is large, locally advanced or metastatic, or is located in an inaccessible site, excisional biopsy or resection cannot be performed. ${ }^{1,6}$ We also believe that FNA samples may be more representative of the tumor due to sampling of multiple areas of tumor by this technique compared with the unidirectional core needle biopsy. Thus, there is a critical need to develop and use efficient strategies and novel technologies for mutation testing of FNA samples. ${ }^{6}$ Further, due to potentially clinically actionable implications carried with the presence of these mutations, proper validation studies are essential for the laboratory test development. This was acknowledged at a symposium on molecular diagnosis on tissues and cells, held in 2011. ${ }^{30}$

Several studies have assessed the suitability of cytological specimens, using fresh or fixed smears or cell blocks, for the detection of somatic mutations in several genes. The genes tested have included EGFR $K R A S, B R A F$ and PIK3CA in the lung specimens and BRAF, RET, RAS, TRK and PPR $\mathrm{in}$ the thyroid nodules. ${ }^{6,7,10,23,30-38}$ Due to the low analytical sensitivity of direct sequencing, ultrasensitive techniques such as high resolution melting, realtime PCR and pyrosequencing have been utilized to improve detection sensitivity. ${ }^{7}$ However, assessment of multiple genes in cytological specimens is sometimes not possible, because traditional platforms require large amounts of DNA. NGS technology can 


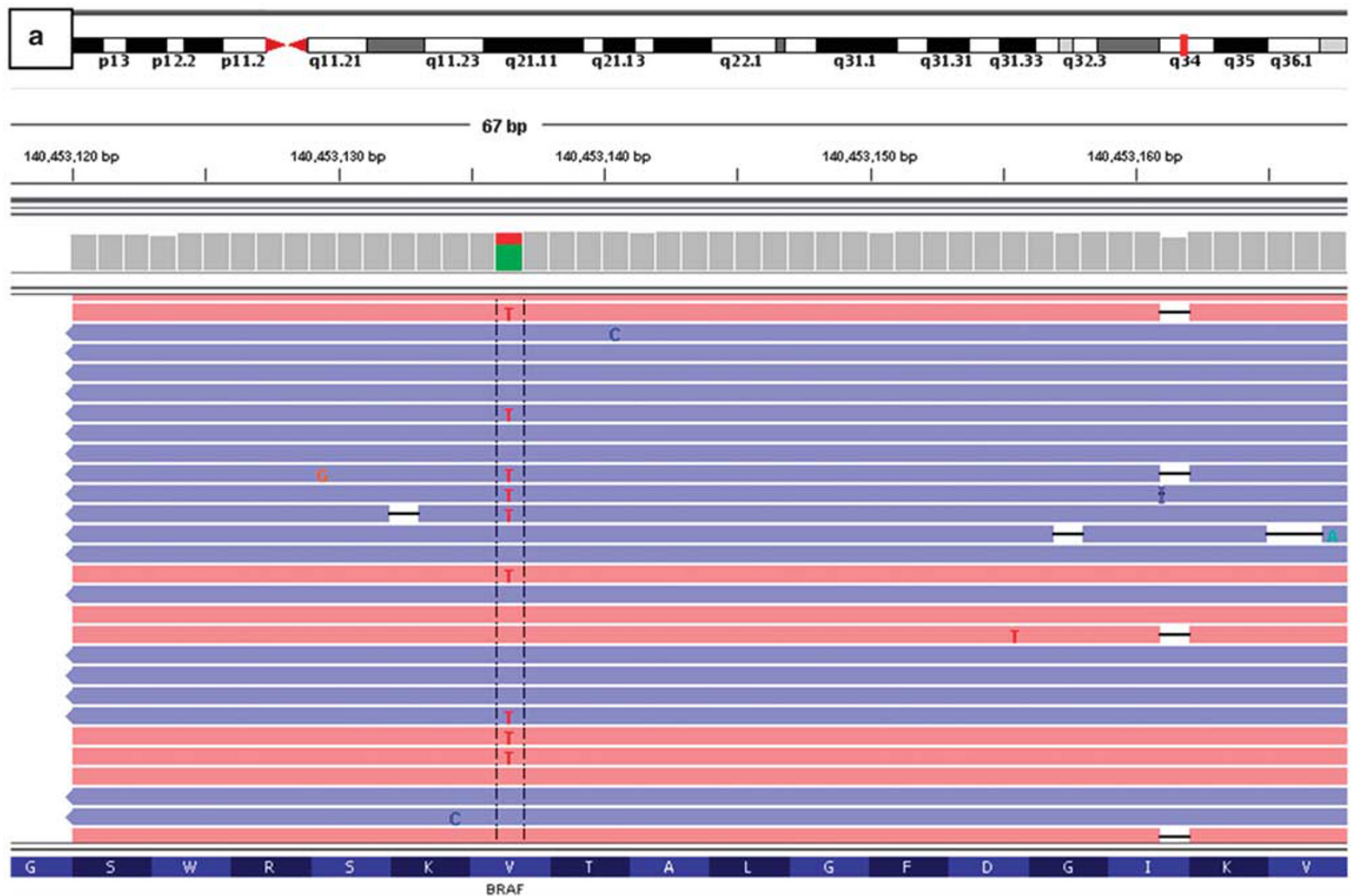

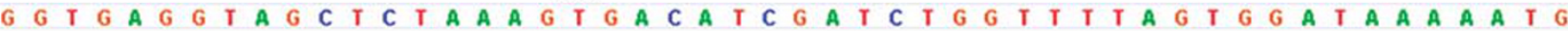

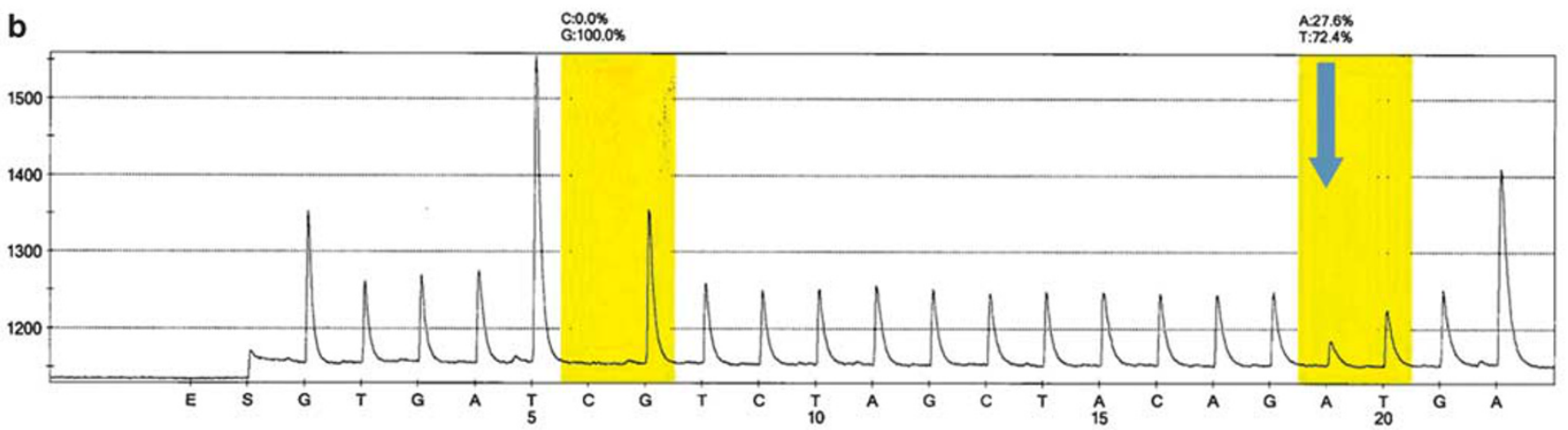

Figure 3 (a) Illustration of a mutation detected in FNA smear by the Ion Torrent next-generation sequencing platform as visualized in IGV (a case of papillary thyroid carcinoma, NM_004333.4(BRAF):c.1799 T > A p.V600E); (b) Same mutation identified by pyrosequencing.

be potentially used to overcome this problem. In our study, we used an Ion PGM NGS platform to detect variants in 46 genes in different types of cytological specimens. The amount of DNA required was markedly less compared with conventional platforms, and it allowed the assessment of multiple genes simultaneously using the same small quantity of DNA. The rationale for selection of the Ion PGM compared with other current NGS platforms such as Illumina Miseq (Illumina Inc., San Diego, CA) was mainly the differences in the DNA input. The DNA requirements for a 46-gene AmpliSeq panel on Ion PGM was markedly less (10 ng) compared with a 48gene TruSeq panel on Illumina Miseq (250 ng). As most of our solid tumor specimens in our laboratory are FNA smears, FFPE cell blocks and core needle biopsies, we were unable to obtain a yield of $250 \mathrm{ng}$ of DNA. Even by lowering the input to $10 \mathrm{ng}$ for NGS testing by Ion PGM, only 31 of the 61 cytological samples had a sufficient DNA concentration by Qubit assessment for the 46 gene mutation panel analysis.

All samples that had sufficient DNA were successfully sequenced by NGS. Thus, adequate DNA concentration appears to be the only prerequisite for successful sequencing. To enhance the DNA yield, in all of our cases DNA extraction was performed following selection of tumor-rich areas. 

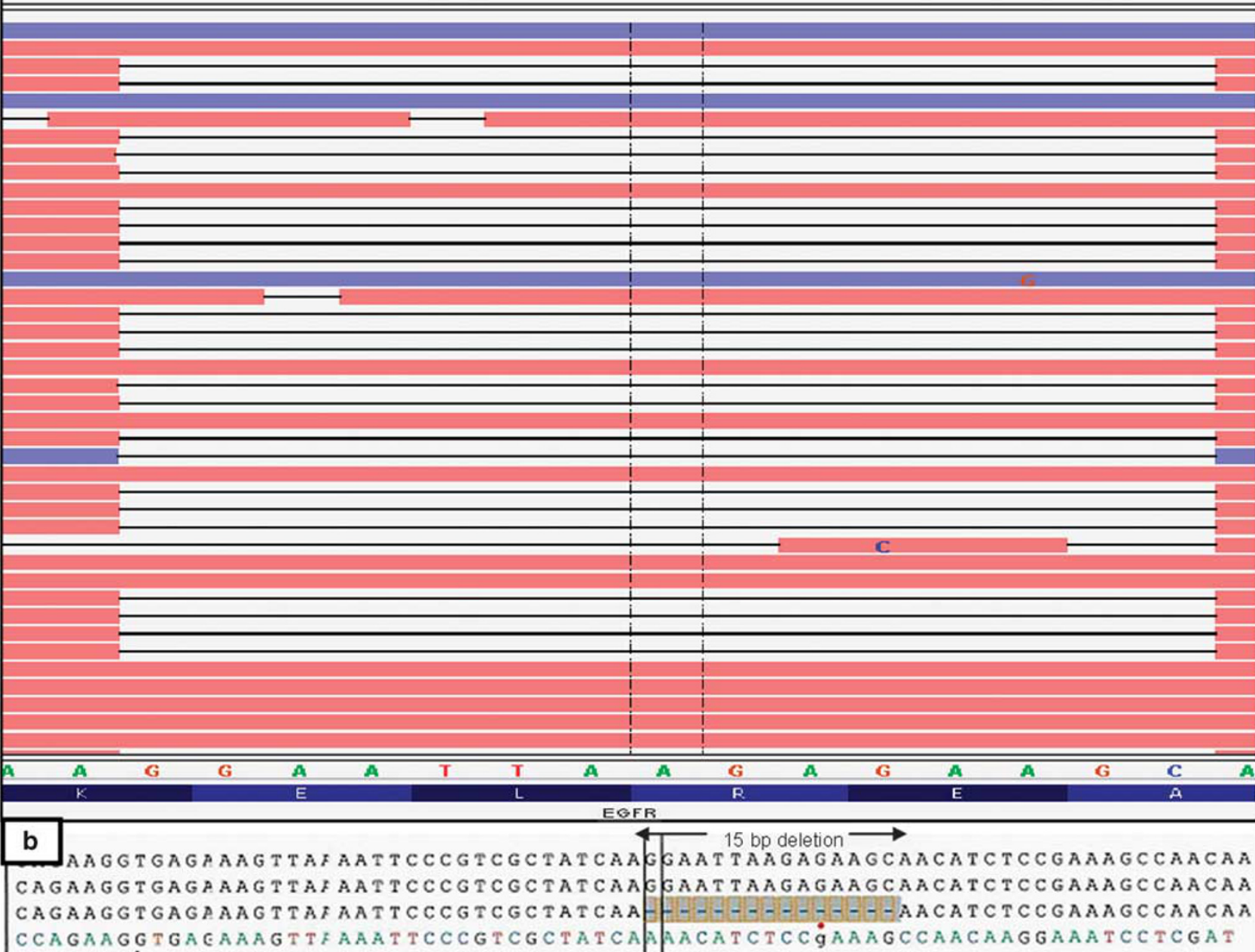

CCAGAAGGTGAGAAAGTTRAAATTCCCGTCGCTATCA

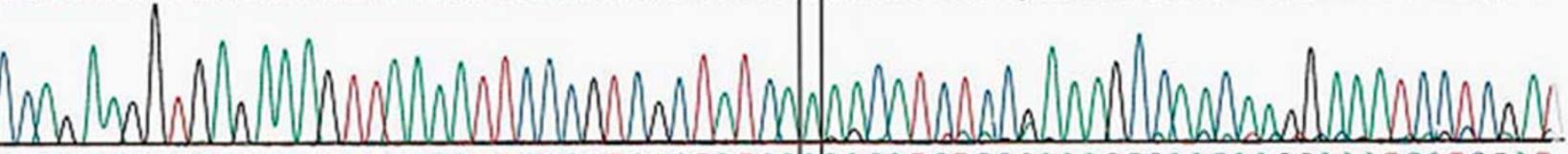

CCAGAAGGTGACAAAGTT2AAATTCCCGTCGCTATCAAAACATCTCCGAAAGCCA A A G A A TCCTCGAT

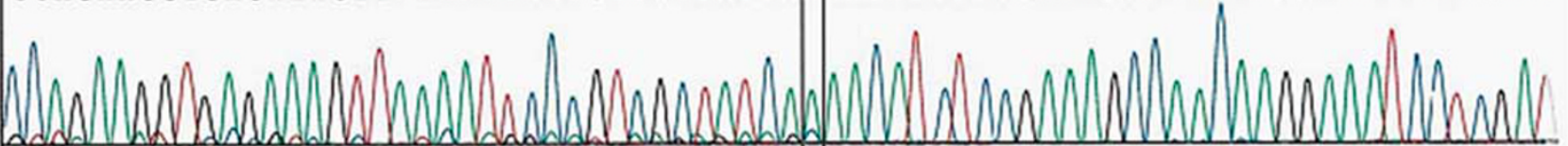

CA A A G T TAGAAGT TAZAATTCCCGTCGCTATCAAGGAATTAAGAGAAGCAACATCTCCGAAAGCCAACAA

CAGAAGGTGAGAAAGTTAZAATTCCCGTCGCTATCAAGGAATTAAGAGAAGCAACATCTCCGAAAGCCAACAA

Figure 4 (a) Illustration of a 15-bp deletion in EGFR gene detected by Ion Torrent next-generation sequencing platform as visualized in IGV (a case of lung adenocarcinoma). (b) Same mutation identified by Sanger sequencing.

We also preselected cases with $>20 \%$ tumor only, where DNA was extracted by manual scraping. In our lab, we routinely perform laser capture microdissection (LCM) on samples with $<20 \%$ tumor. The NGS-based testing is not yet validated on the LCM samples.

There was no difference in the median tumor percentages between the groups of 31 cytological specimens that yielded sufficient DNA compared with 30 cases that yielded with insufficient DNA. One potential explanation is that we did not measure the tumor surface area on the slides for each of the cases. Second, for our NGS testing, we require at least $10 \mathrm{ng}$ of DNA in $12 \mu \mathrm{l}$ of nuclease-free water. Majority of our study group included left-over DNA samples from clinical specimens that had undergone either retrospective or concurrent testing by $\geq 1$ of the conventional testing platforms. Thereby, following DNA extraction, DNA was eluted in sufficient volume of nuclease-free water for utilization for several clinical tests. Thus, for certain samples, in spite of availability of sufficient total 


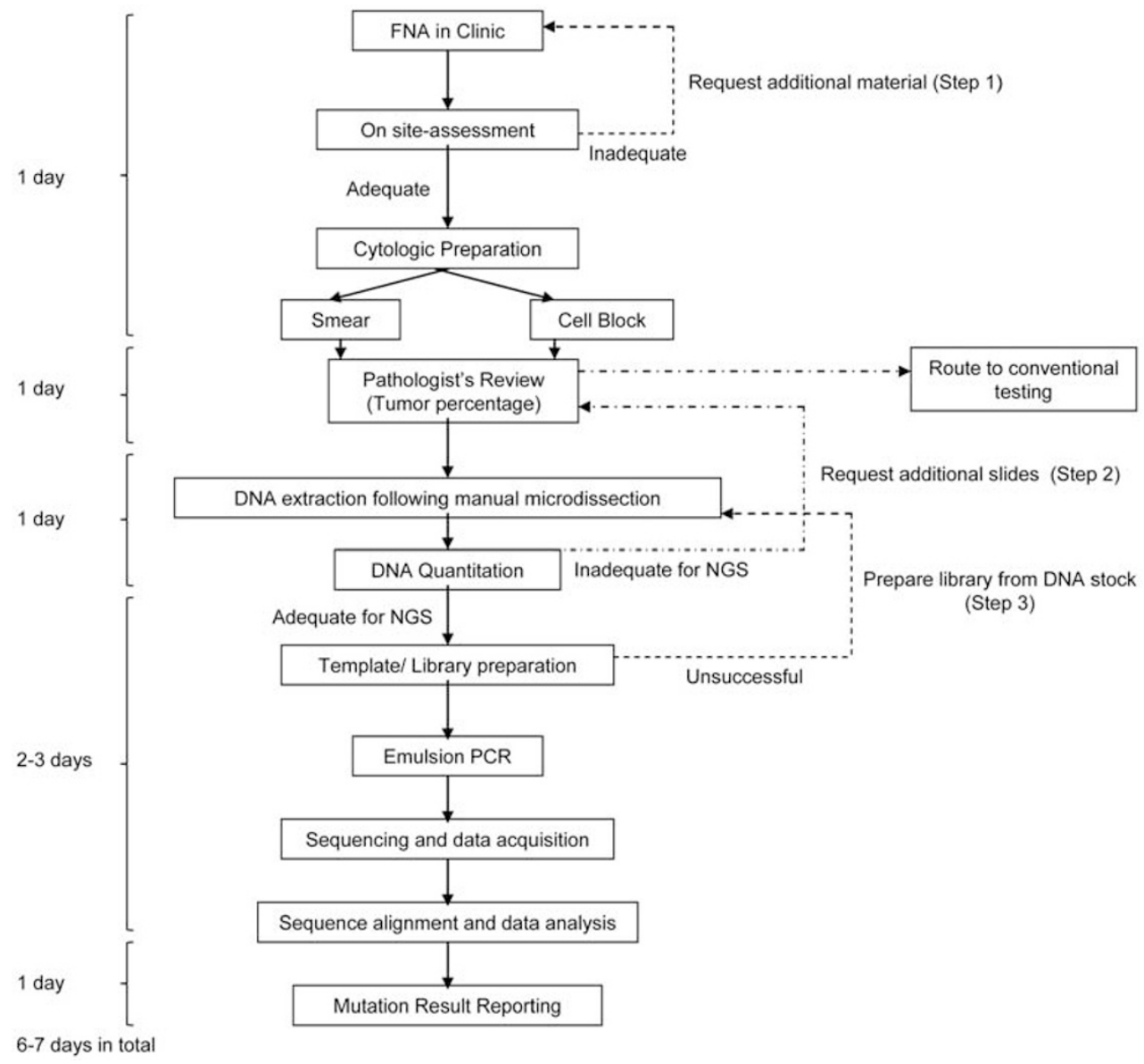

Figure 5 Illustration of optimized workflow of cytological specimens for next-generation sequencing technique in our clinical laboratory.

DNA, the concentration of DNA precluded NGS testing. If these cytological specimens had been extracted solely for NGS purposes, concentration may have been modified to achieve a total of $10 \mathrm{ng}$ DNA to accommodate NGS-based testing.

Our study included stained smears as well as unstained cell block sections. Both types of specimens underwent successful sequencing by NGS, and neither of them showed better performance compared with each other. The success we had analyzing archival, stained cytological smears in this study is particularly convenient. Of the 16 FNA smears, we had included 3 methanol-fixed Diff-Quik-stained smears in addition to the 13 ethanol-fixed Papanicolaou-stained smears. The type of cytological stain and fixative did not appear to influence the performance of this test. This experience is in contrast to earlier studies in which DNA extracted from May-Grunwald-Giemsa-stained cytological smears seemed to be of superior quality compared with DNA extracted from Papanicolaou-stained slides. ${ }^{38}$ With the cell blocks, similar to the surgical biopsy specimens, we did not observe any sequence artifacts associated with formalin fixation, such as transitional mutations. ${ }^{39,40}$ Further, DNA from all the samples extracted from cell blocks underwent successful PCR amplification for sequencing.
In this study, there was $100 \%$ concordance between the mutations detected by conventional sequencing platforms and NGS. However, additional variants were identified by NGS in approximately $60 \%$ of the cases, with far less DNA required for analysis. The advantages of NGS testing seem clear. One can argue that the clinical significance of some of these additional gene variants is unclear, but longterm follow-up will likely lead to a better understanding. For example, due to broader amplicon coverage, the p.Met541Leu variant in exon 10 of KIT gene was frequently identified by NGS, whereas Sanger sequencing in our laboratory has been designed only for exons 9, 11, 13 and 17. The pMet541Leu variant has been described as a germline polymorphism in normal individuals. ${ }^{41}$ However, there have been conflicting results in another study that showed significantly increased frequency of this variant in patients with chronic myelogenous leukemia compared with healthy volunteers. ${ }^{42}$ Thus, in the long run, NGS results may help determine the clinical significance of variants that currently are poorly understood.

A large number of samples of lung adenocarcinomas were included in our study. FNA of lung masses is a common diagnostic modality at our institution. Critical to the mutational analysis of lung tumors is 
the detection of point mutations as well as deletions and insertions in the EGFR gene. Detection of indels in NGS data is known to be difficult. In this study, all six cytological specimens from lung adenocarcinomas with known deletions in EGFR were identified. In two cases, deletions were not called by the Torrent Variant Caller. However, deletions could be visualized on the mapped reads in IGV, and in such cases, alternative computational approaches and indel detection softwares may be of help. ${ }^{43}$ The number of base pairs deleted also correlated with the Sanger data. Thus, lung cytological specimens are suitable for mutation detection by NGS.

We only used fixed cytological specimens for NGS in this study. Fresh specimens contain unaltered DNA, free from fixation and processing, and theoretically will yield better results. However, it is not possible to accurately quantify tumor percentage or separate tumor cells from contaminating non-tumor cells using fresh samples. Therefore, possible nonrepresentation of tumor makes it impossible to predict the outcome of mutational results using fresh tissue. Ulivi et $a l^{7}$ showed that fixed stained cytological specimens are more reliable for molecular analysis than fresh specimens. In their study, 2 of the 36 cases in which DNA was obtained from fresh cytological specimens showed false-negative mutation results for EGFR and KRAS testing. The false-negative results were attributed to lack of accurate cancer cell selection and quantification.

A limitation of our study includes the absence of a parallel evaluation of matched cytological and concurrent surgical specimens from the same patient. There were only three cases with concurrent (within 3 months of FNA) cytological and excisional biopsy or surgical resection specimens that were sent to the laboratory for mutational assessment. Two of these samples analyzed by conventional platforms did not show any mutations in the tested genes, which was consistent with FNA findings. One case did not yield any PCR product. All three cases had limited amount of DNA left over for NGS analysis. Our study also looked at the most frequent tumors that undergo cytological evaluation. Extending the study to other types of malignancies that undergo FNA would further validate the methods used.

We used our experience to propose an optimized workflow for cytology specimens for NGS testing in our laboratory (Figure 5). The most challenging part was that only about $50 \%$ of the cases qualified for testing by NGS. We were unable to determine any particular characteristic of the specimens that yielded the desired amount of DNA. As our study is retrospective, we presume that pre-dilution of DNA for other testing may have been a confounding factor. For this reason, we suggest that on-site adequacy assessment of FNA specimens should be made for both morphological analysis and molecular studies. Further, as smears were as good as cell blocks for NGS testing, additional FNA passes performed specifically for molecular testing may contribute to greater success (Figure 5, step 1). If extracted DNA is of inadequate quality (Figure 5, step 2), requesting additional smear slides to enhance the DNA concentration may be attempted, before routing to a conventional testing platform. In any case, one of the critical steps included tumor enrichment by pathologist's review of the slides. Manual microdissection of tumor-rich areas significantly enhanced DNA yield in cytological specimens where tumor cells are closely intermixed with contaminating non-malignant cells. Following DNA extraction, if the library preparation is unsuccessful, the process can be repeated from the DNA stock (Figure 5, step 3). Due to high false-positive rate and generation of clinically actionable results by this test, we used the following criteria to establish the validity of any variant call. Minimum criteria included uniformly high coverage with a minimum of 300000 AQ20 alignment reads, mutation frequency of $5-10 \%$, with presence of SNVs in both forward and reverse strands. All variant calls were confirmed by an alternate platform unless the SNV had been well established in our patient cohort based on validation studies on other samples (data not shown). With optimization, NGS testing seems very promising in a clinical laboratory setting on cytology specimens. After streamlining the appropriate steps in the workflow, the turnaround time for reporting molecular profiling results from the time of FNA approaches approximately 1 week for timely patient care.

In summary, this is the first study to demonstrate the feasibility of using NGS-based methods to perform gene mutation analysis in routine cytological specimens obtained by FNA, including stained smears and cell blocks. The implications of this study are broad. Mutational profiling of multiple genes is possible using an extremely low quantity of DNA (nanograms), which can be extracted from specimens obtained by FNA, thereby enhancing the utility of the FNA approach. We believe that NGSbased gene mutation analysis is a valuable addition to the workup of FNA specimens obtained from patients with various tumors.

\section{Disclosure/conflict of interest}

The authors declare no conflict of interest.

\section{References}

1 Yung RC, Otell S, Illei $\mathrm{P}$, et al. Improvement of cellularity on cell block preparations using the socalled tissue coagulum clot method during endobronchial ultrasound-guided transbronchial fine-needle aspiration. Cancer Cytopathol 2012;120:185-195.

2 Hirsch FR, Wynes MW, Gandara DR, et al. The tissue is the issue: personalized medicine for non-small cell lung cancer. Clin Cancer Res 2010;16:4909-4911. 
3 Cagle PT, Allen TC, Dacic S, et al. Revolution in lung cancer: new challenges for the surgical pathologist. Arch Pathol Lab Med 2011;135:110-116.

4 Corrias A, Einaudi S, Chiorboli E, et al. Accuracy of fine needle aspiration biopsy of thyroid nodules in detecting malignancy in childhood: comparison with conventional clinical, laboratory, and imaging approaches. J Clin Endocrinol Metab 2001;86:4644-4648.

5 Monaco SE, Pantanowitz L, Khalbuss WE, et al. Cytomorphological and molecular genetic findings in pediatric thyroid fine-needle aspiration. Cancer Cytopathol 2012;120:342-350.

6 Aisner DL, Deshpande C, Baloch Z, et al. Evaluation of EGFR mutation status in cytology specimens: an institutional experience. Diagn Cytopathol 2013;41:316-323.

7 Ulivi P, Romagnoli M, Chiadini E, et al. Assessment of EGFR and K-ras mutations in fixed and fresh specimens from transesophageal ultrasound-guided fine needle aspiration in non-small cell lung cancer patients. Int J Oncol 2012;41:147-152.

8 Klijanienko J, Couturier J, Bourdeaut F, et al. Fineneedle aspiration as a diagnostic technique in 50 cases of primary Ewing sarcoma/peripheral neuroectodermal tumor. Institut Curie's experience. Diagn Cytopathol 2012;40:19-25.

9 Saieg MA, Geddie WR, Boerner SL, et al. The use of FTA cards for preserving unfixed cytological material for high-throughput molecular analysis. Cancer Cytopathol 2012;120:206-214.

10 Santis G, Angell R, Nickless G, et al. Screening for EGFR and KRAS mutations in endobronchial ultrasound derived transbronchial needle aspirates in nonsmall cell lung cancer using COLD-PCR. PloS One 2011;6:e25191.

11 Pirker R, Herth FJF, Kerr KM, et al. Consensus for EGFR mutation testing in non-small cell lung cancer: results from a European workshop. J Thorac Oncol 2010;5:1706.

12 Colanta A, Lin O, Tafe L, et al. BRAF mutation analysis of fine-needle aspiration biopsies of papillary thyroid carcinoma: impact on diagnosis and prognosis. Acta Cytol 2011;55:563-569.

13 Singh RR, Patel KP, Routbort MJ, et al. Clinical validation of a next generation sequencing screen for mutational hotspots in 46 cancer-related genes. J Mol Diagn 2013; advance online publication, 25 June 2013; pii: S1525-S1578(13) 00090-1; doi:10.1016/j.jmoldx. 2013.05.003 (e-pub ahead of print).

14 Rothberg JM, Hinz W, Rearick TM, et al. An integrated semiconductor device enabling non-optical genome sequencing. Nature 2011;475:348-352.

15 Thorvaldsdottir H, Robinson JT, Mesirov JP. Integrative Genomics Viewer (IGV): high-performance genomics data visualization and exploration. Brief Bioinform 2013;14:178-192.

16 Routbort MJ, Handal B, Patel KP, et al. OncoSeek-a versatile annotation and reporting system for next generation sequencing-based clinical mutation analysis of cancer specimens. J Mol Diagn 2012;14:637-748.

17 Baloch ZW, Cibas ES, Clark DP, et al. The National Cancer Institute Thyroid Fine Needle Aspiration State of the Science Conference: a summation. Cytojournal 2008;5:6.

18 Layfield LJ, Abrams J, Cochand-Priollet B, et al. Postthyroid FNA testing and treatment options: a synopsis of the National Cancer Institute Thyroid Fine Needle Aspiration State of the Science Conference. Diagn Cytopathol 2008;36:442-448.
19 Layfield LJ, Cibas ES, Gharib H, et al. Thyroid aspiration cytology: current status. CA Cancer J Clin 2009;59:99-110.

20 Hassell LA, Gillies EM, Dunn ST. Cytologic and molecular diagnosis of thyroid cancers: is it time for routine reflex testing? Cancer Cytopathol 2012;120: 7-17.

21 Cerutti J. Employing genetic markers to improve diagnosis of thyroid tumor fine needle biopsy. Curr Genomics 2011;12:589-596.

22 Ferraz C, Eszlinger M, Paschke R. Current state and future perspective of molecular diagnosis of fineneedle aspiration biopsy of thyroid nodules. J Clin Endocrinol Metab 2011;96:2016-2026.

23 Marchetti I, Lessi F, Mazzanti CM, et al. A morphomolecular diagnosis of papillary thyroid carcinoma: BRAF V600E detection as an important tool in preoperative evaluation of fine-needle aspirates. Thyroid 2009;19:837-842.

24 Oler G, Cerutti JM. High prevalence of BRAF mutation in a Brazilian cohort of patients with sporadic papillary thyroid carcinomas. Cancer 2009;115: 972-980.

25 Xing M. Prognostic utility of BRAF mutation in papillary thyroid cancer. Mol Cell Endocrinol 2010; 321:86-93.

26 Nikiforova MN, Nikiforov YE. Molecular diagnostics and predictors in thyroid cancer. Thyroid 2009;19: 1351-1361.

27 Adeniran AJ, Theoharis C, Hui P, et al. Reflex BRAF testing in thyroid fine-needle aspiration biopsy with equivocal and positive interpretation: a prospective study. Thyroid 2011;21:717-723.

28 Yip L, Nikiforova MN, Carty SE, et al. Optimizing surgical treatment of papillary thyroid carcinoma associated with BRAF mutation. Surgery 2009;146: 1215-1223.

29 Nucera C, Lawler J, Hodin R, et al. The BRAFV600E mutation: what is it really orchestrating in thyroid cancer? Oncotarget 2010;1:751.

30 Boyd C, Boyle DP. Molecular diagnosis on tissues and cells: how it affects training and will affect practice in the future. Cytopathology 2012;23:286-294.

31 da Cunha Santos G, Saieg MA, Geddie W, et al. EGFR gene status in cytological samples of nonsmall cell lung carcinoma. Cancer Cytopathol 2011;119:80-91.

32 Fassina A, Gazziero A, Zardo D, et al. Detection of EGFR and KRAS mutations on trans-thoracic needle aspiration of lung nodules by high resolution melting analysis. J Clin Pathol 2009;62:1096.

33 Garcia-Olive I, Monso E, Andreo F, et al. Endobronchial ultrasound-guided transbronchial needle aspiration for identifying EGFR mutations. Eur Respir J 2010;35:391-395.

34 Smouse JH, Cibas ES, Jänne PA, et al. EGFR mutations are detected comparably in cytologic and surgical pathology specimens of nonsmall cell lung cancer. Cancer Cytopathol 2009;117:67-72.

35 van Eijk R, Licht J, Schrumpf M, et al. Rapid KRAS, EGFR, BRAF and PIK3CA mutation analysis of fine needle aspirates from non-small-cell lung cancer using allele-specific qPCR. PloS One 2011;6: e17791.

36 Marchetti I, Iervasi G, Mazzanti CM, et al. Detection of the BRAF(V600E) mutation in fine needle aspiration cytology of thyroid papillary microcarcinoma cells selected by manual macrodissection: an easy tool to 
improve the preoperative diagnosis. Thyroid 2012; 22:292-298.

37 Cantara S, Capezzone M, Marchisotta S, et al. Impact of proto-oncogene mutation detection in cytological specimens from thyroid nodules improves the diagnostic accuracy of cytology. J Clin Endocrinol Metab 2010;95:1365-1369.

38 Kawauchi S, Sugimoto S, Liu XP, et al. Influence of cytological stains on comparative genomic hybridization analysis for DNA extracted from cytological smears. Oncol Rep 2007;18:1219-1223.

39 Quach N, Goodman MF, Shibata D. In vitro mutation artifacts after formalin fixation and error prone translesion synthesis during PCR. BMC Clin Pathol 2004;4:1-5.
40 Do H, Dobrovic A. Dramatic reduction of sequence artefacts from DNA isolated from formalin-fixed cancer biopsies by treatment with uracil-DNA glycosylase. Oncotarget 2012;3:546-558.

41 Grabellus F, Worm K, Sheu SY, et al. The prevalence of the c-kit exon 10 variant, M541L, in aggressive fibromatosis does not differ from the general population. J Clin Pathol 2011;64:1021-1024.

42 Inokuchi K, Yamaguchi H, Tarusawa M, et al. Abnormality of c-kit oncoprotein in certain patients with chronic myelogenous leukemia-potential clinical significance. Leukemia 2002;16:170-177.

43 Yeo ZX, Chan M, Yap YS, et al. Improving indel detection specificity of the Ion Torrent PGM Benchtop Sequencer. PLoS One 2012;7:e45798. 